\title{
Comentários sobre Em Busca do Conceito de Linha de Pesquisa e outras Reflexões sobre o Tema
}

\author{
Jaime Evaldo Fensterseifer
}

A escolha do tema Linhas de Pesquisa para a seção Documentos e Debates deste número da Revista de Administração Contemporânea (RAC) foi, sem dúvida, muito feliz e oportuna por várias razões: pela sua importância na organização das atividades de pesquisa e, conseqüentemente, no desenvolvimento do conhecimento científico e tecnológico; pelo amplo uso que fazem do conceito (ou conceitos) de linha de pesquisa a Capes, tanto na avaliação de propostas de novos cursos como na avaliação dos Programas de Pós-Graduação (PPG) integrantes do Sistema Nacional de Pós-Graduação, e o CNPq, no Diretório dos Grupos de Pesquisa no Brasil; e, apesar da reconhecida importância do conceito pela comunidade acadêmica, pela confusão que existe sobre ele.

A minha expectativa em relação ao ensaio do Professor Jairo Eduardo BorgesAndrade foi plenamente confirmada, não tendo havido qualquer excesso de confiança. Mas a concordância com o texto apresentado, se, por um lado, me deixa feliz e rassuré, por outro torna frustrante o trabalho de escrever a réplica. Assim, não tenho outro caminho senão o de tentar acrescentar e complementar alguns aspectos levantados no ensaio. E o espaço que vislumbro como contribuição é o de aprofundar um pouco a questão da hierarquia entre área de concentração, linhas de pesquisa e projetos, bem como apresentar algumas reflexões que podem contribuir para introduzir alguns elementos dinâmicos à definição apresentada.

\section{Sobre a Hierarquia entre Área de Concentração, Linhas de Pesquisa e Projetos}

A importância desta discussão reside no fato de que a hierarquia estabelece os limites dentro dos quais linhas de pesquisa podem ser definidas. O Professor Jairo comentou com muita propriedade esta hierarquia do geral para o específico, sugerindo até mesmo um “continuum de 'frouxidão' progressiva”, sendo o nível inferior o mais bem definido. Eu quero aqui incluir nesta discussão uma segunda hierarquia, a do lado esquerdo do diagrama abaixo, relacionada à primeira justa- 
mente no nível de interesse da questão em discussão, constituindo assim um ponto de amarração para reduzir a "frouxidão" do conceito de linha de pesquisa.

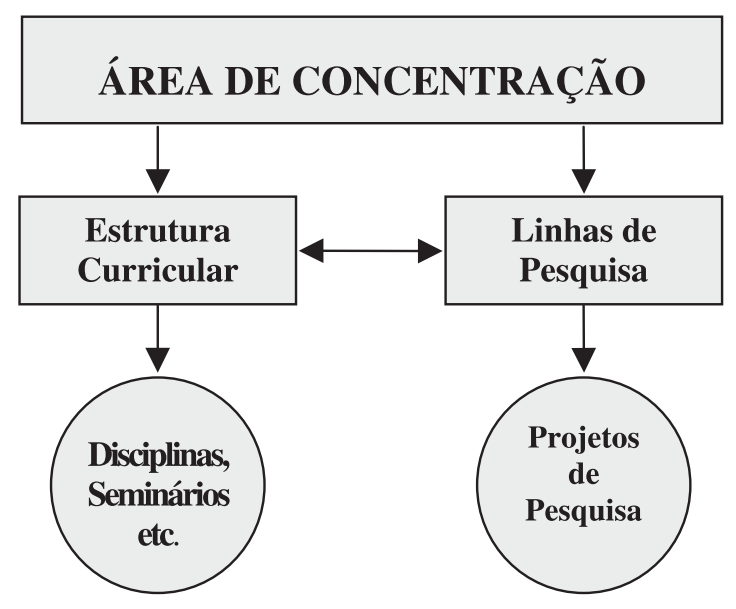

A Estrutura Curricular e as Linhas de Pesquisa dão sustentação às atividades de ensino e de pesquisa de uma Área de Concentração. A implementação da estrutura curricular se dá por meio de disciplinas, seminários e atividades afins, e a implementação de uma linha de pesquisa se dá por meio de projetos de pesquisa. As unidades básicas de ação são, portanto, disciplinas (e atividades equivalentes) e projetos de pesquisa, representadas nos círculos do diagrama; tudo o mais, representado nos retângulos, são concepções que existem para dar nexo, consistência e direção a essas atividades.

O ponto principal a destacar nesta visão sistêmica representada pelo diagrama é a relação de influência mútua entre Estrutura Curricular e Linhas de Pesquisa. Como uma estrutura curricular é definida de maneira mais precisa e deve guardar uma relação quase simbiótica com as linhas de pesquisa, existe aí um forte vínculo bidirecional a ser permanentemente respeitado, tanto na concepção das linhas de pesquisa como dinamicamente ao longo de seu desenvolvimento. Este vínculo constitui, conforme colocado inicialmente, importante ponto de amarração da linha de pesquisa, que possui, assim, além dos limites estabelecidos pela sua relação vertical com Área de Concentração e Projetos de Pesquisa, os limites da sua relação horizontal com a Estrutura Curricular.

Esta visão sistêmica tem relevância também na análise da consistência interna de uma Área de Concentração e, conseqüentemente, de uma proposta de Programa, pois explicita as relações que devem ser respeitadas entre os elemen- 
tos constituintes de cada área de concentração. A consistência da proposta, nesta visão, consiste justamente na coerência vertical de cada área de concentração, nas suas vertentes ensino e pesquisa e na coerência horizontal entre Estrutura Curricular e Linhas de Pesquisa.

Finalmente, é preciso salientar ainda que o conceito de Linha de Pesquisa deve ser flexível. Neste sentido, o desafio que temos é o de encontrar formas de diminuir a sua “frouxidão”, sem que ele perca a sua necessária flexibilidade. Ele deve, portanto, representar a mesma coisa para todos e, ao mesmo tempo, possuir maleabilidade suficiente para acomodar as especificidades de cada área do conhecimento, e mesmo a diversidade de propostas que existe dentro de uma mesma área, como é o caso da Administração.

\section{O Ciclo de Vida de uma Linha de Pesquisa}

Os elementos dinâmicos que podem e, na minha visão, devem ser incorporados à noção de Linha de Pesquisa, são os que advêm da utilização do conceito de ciclo de vida. A metáfora do ciclo de vida, que encontrou várias aplicações na área de Administração, também pode ser utilizada para enriquecer a nossa compreensão sobre Linha de Pesquisa, a sua evolução e a sua dinâmica no processo de geração de conhecimento, aumentando assim a sua eficácia como forma de organizar as atividades de pesquisa de um PPG.

O Professor Jairo coloca, e eu concordo com a colocação, que uma importante força “impulsionadora do uso da expressão 'linha de pesquisa' a partir da segunda metade da década de 80 , foi o reconhecimento de que o processo contemporâneo de pesquisa deve ser coletivo e articulado institucionalmente”. A esta força impulsionadora do uso da expressão eu acrescentaria uma outra, que se complementa a esta e, na minha visão, justifica pensar na evolução de uma linha de pesquisa em termos de ciclo de vida: trata-se da natureza cumulativa do processo de geração do conhecimento e do papel importante da concepção de Linha de Pesquisa para dar um norte a este processo.

Aceitar que linhas de pesquisa possuem um ciclo de vida, implica aceitar que elas são concebidas, nascem, se desenvolvem, atingem a maturidade, passam por uma fase de declínio e morrem. Comentarei brevemente cada uma destas fases, delimitando desde já que tratarei apenas de Linhas de Pesquisa que se desenvolvem no âmbito de um PPG e coerentes com a visão representada pelo diagrama da seção anterior. 
A definição de Linha de Pesquisa proposta pelo Professor Jairo tem particular relevância na fase de concepção, pois elabora com muita propriedade os elementos que devem fazer parte de uma linha de pesquisa e é de grande valia para os PPG no seu esforço de organizar as atividades de pesquisa que vão dar sustentação às Áreas de Concentração e, conseqüentemente, à Proposta do Programa. Os meus comentários na seção anterior acrescentam a vinculação ensino-pesquisa, que também deve fazer parte da discussão que culminará na concepção das linhas de pesquisa de um PPG.

Conforme vimos na seção anterior, uma linha de pesquisa é implementada por meio de projetos. O nascimento ocorre, portanto, quando a linha tiver projetos. E seu desenvolvimento se dá mediante a execução dos projetos que, tendo um prazo para terminar, se renovam constantemente ao longo do ciclo de vida da linha de pesquisa, para refletirem os avanços nas questões pertinentes à ela. Os projetos constituem, portanto, a unidade básica de uma linha de pesquisa e são o que lhe confere dinamicidade.

Quando a linha de pesquisa gera avanços no conhecimento da temática em questão, materializados por meio de produção científica publicada em periódicos de primeira linha, diz-se que a linha de pesquisa está consolidada. A fase de maturidade inicia-se com a consolidação da linha e vai até que surgem os primeiros sinais de declínio, em que os temas abordados diminuem em pertinência e relevância e o meio acadêmico perde o interesse neles, processo este que culmina com a morte da linha de pesquisa.

A forma descrita acima em que uma linha de pesquisa morre, ou seja, se extingue, não é a única e, tampouco, na minha visão, a desejável. Como partimos da premissa de que uma linha de pesquisa deve ser dinâmica e evoluir ao longo do tempo, a sua forma de extinção descrita acima corresponde, metaforicamente, como veremos a seguir, à extinção de uma espécie. A fase final do ciclo de vida não deveria ser, portanto, a extinção da linha de pesquisa, mas sim, para tomar emprestado mais um conceito da Biologia, uma transmutação. Apoiandome na definição proposta pelo Professor Jairo, esta transmutação poderia ser uma mudança no rumo, já que o rumo é determinado num dado contexto ou realidade, que muda ao longo do tempo, ou no limite das fronteiras do campo específico do conhecimento (grau de abrangência ou, metaforicamente, nicho da linha), ou na orientação teórica, ou, ainda, nos procedimentos considerados adequados neste processo.

A partir da discussão acima, fica claro que a metáfora do ciclo de vida aqui utilizada deve ser vista no sentido evolucionário das espécies, em que a morte pode significar tanto a extinção como a evolução para outra espécie. Porém, em 
se tratando, no caso de uma Linha de Pesquisa, de uma concepção artificial, torna-se possível defini-la de forma a se poder gerir a sua evolução, induzindo mutações já nos primeiros sinais de declínio, ou mesmo antes deles, atuando nos elementos pertinentes constituintes de sua definição. Teríamos, assim, ao invés de uma seleção natural, uma seleção administrada.

É evidente que mudanças paradigmáticas em determinada área do conhecimento, podem abalar uma linha de pesquisa nas suas estruturas e provocar a sua extinção; mas, se ela for concebida de maneira suficientemente flexível, poderá sobreviver mesmo a este tipo de mudança, por meio de uma transmutação. Uma linha de pesquisa deve, portanto, ser pensada e concebida para ser duradoura, refletindo objetivos de longo prazo e não apenas aqueles do seu conjunto atual de projetos, que reflete meramente a fase do seu ciclo de vida em que ela se encontra.

Finalmente, a visão dinâmica aqui apresentada ressalta a importância de uma adequada concepção da linha de pesquisa, pois desta concepção depende crucialmente o grau de administrabilidade de sua evolução; ela deve ser definida, portanto, de maneira a aumentar as suas possibilidades de evolução e assim reduzir os riscos de uma extinção prematura. Tenho observado, nestes dez anos de envolvimento na avaliação dos PPG de Administração na Capes, que existe na área alta rotatividade nas linhas de pesquisa e que as propostas de boa parte dos PPG deixam muito a desejar em termos de consistência interna, sendo a concepção das linhas de pesquisa o elemento mais destoante do sistema. Ambas as constatações constituem evidências de problemas de concepção, problemas estes que certamente não ocorrem somente na área de Administração. Mas esta perspectiva longitudinal revela também a existência de bons exemplos de Programas que, mesmo se na sua origem definiram burocraticamente as linhas de pesquisa apenas para atender as exigências da Capes mediante um mero agrupamento, não raro incongruente, dos projetos de pesquisa existentes, reconceberam-nas e hoje as geram dentro de uma visão e de propósitos mais alinhados com as idéias aqui apresentadas. E não é mera coincidência que estes Programas são os que possuem hoje, além de maior produtividade em pesquisa, uma produção científica mais consistente e coerente com a sua proposta.

\section{Considerações Finais}

As colocações feitas nesta réplica são reflexões, que visam a contribuir para a discussão de um tema que faz parte do dia-a-dia da vida de um PPG e que merece uma discussão maior por parte da comunidade acadêmica. O texto do 
Professor Jairo representa um marco importante nesta empreitada, pois resgata de maneira sistemática as várias definições existentes, seus vários usos e faz importantes avanços na direção de uma definição que possa ser amplamente aceita pela comunidade acadêmica.

A discussão sobre ciclo de vida aqui apresentada foi um tanto simplista e requer uma elaboração maior. Tratam-se, no presente estágio, de elocubrações de um fim de semana. E se alguém me perguntar se eu não tinha nada melhor para fazer num fim de semana, a resposta é: tinha sim! Mas o prazo que me foi dado pelo editor para esta réplica, não me permitiu! 